\title{
América Latina ¿Hacia qué nuevo orden internacional?**
}

Actualmente, existe una percepción generalizada acerca de la necesidad de introducir cambios fundamentales en el orden económico y político internacional. Pucde afirmarse que tanto en los países desarrollados capitalistas como en los socialistas, y más aun entre los países subdesarrollados, son muy pocos los que vacilan en afirmar que el orden internacional de la postgucrra ya no contempla en forma adecuada las necesidades de un mundo profundamente modificado por el surgimiento de nuevos Estados, la redefinición de las relaciones entre las superpotencias, el desafío planteado en los países centrales por las nuevas exigencias del desarrollo postindustrial, la escasez de recursos y la pobreza de la mayoría de la población mundial.

Sin embargo, este consenso no trasciende, en lo esencial, el reconocimiento de que ciertos cambios deberían operarse. A partir de esta coincidencia, las posturas son múltiples y revelan divergencias profundas. Así, los cambios requeridos pueden afectar los fundamentos del sistema o, simplemente, provocar cambios en las reglas de juego del sistema vigente; pueden referirse a un aumento de la eficiencia en el uso de los instrumentos conocidos o a la utilización de nuevos instrumentos y estrategias.

Por una parte, la actual coyuntura revela con claridad que tanto los países desarrollados como los subdesarrollados incluidos en el mundo capitalista trabajan en la elaboración de los lineamientos básicos de un predecible nuevo orden internacional. Es menos claro, en cambio, que las premisas básicas de ese nuevo orden alienten objetivos comunes; por el contrario, no sólo dificren entre sí, sino que, al menos parcialmente, resultan antagónicas.

En este sentido, resulta útil concentrar la atención más allá de las

- Ponencia presentada al Seminario "América Iatina y el Nuevo Orden Eco. nómico Internacional" organizado en Viña del Mar, entre los días 7 y 11 de enero de 1979, por el cPU y el riaL. 
posiciones oficialmente asumidas por las partes en las tendencias económicas y políticas detectadis en los pafses del Norte y del Sur, $y$, a partir de las mismas en el tipo de orden económico internacional que subyace bajo la inevitable retórica utilizada en la exposición de los casos.

La trabajosa elaboración de los lineamientos del Nori - tal como surgen de la Declaración y Programa de Acción en torno al establecimiento de un Nuevo Orden Económico Internacional-, la Carta de Derechos y Deberes Económicos de los Estados, el Programa Integrado de la unctad, etc., refleja al mismo tiempo tanto la fuerza como los puntos débiles del Sur como bloque.

Resulta difícil hallar, detrás de los justos reclamos de los países del Tercer Mundo, un marco teórico sólido y coherente que sirva de referencia a las demandas y proposiciones planteadas a los países industrializados.

Esta suerte de vaguedad ideológica es el resultado de la transacción realizada entre las distintas posturas e intereses de países que, además de poseer distintos niveles de desarrollo, sostienen objetivos divergentes en el mediano y largo plazo y, sobre todo, una interpretación distinta del modelo o vía de desarrollo más adecuado al contexto interna. cional donde se desenvuelven.

Ello explica que algunas demandas incluidas en el programa básico del NOEI incluyan implícitamente la convicción de que el elemento clave del desarrollo nacional es el comercio exterior, y tiendan, en consecuencia, a lograr una inserción más justa y equilibrada en la economía internacional. Así, las demandas para facilitar el acceso de productos manufacturados provenientes de paises subdesarrollados a los mercados de países industriales; los reclamos de transferencia acclerada de tecnologia, de protección contra las bruscas fluctuaciones de precios de los productos primarios y de revisión de la estructura de mercado y de los mecanismos de precios para los productos pri. marios, son parte de un programa destinado a profundizar y mejorar un sistema cuyo núcleo dinámico es el comercio internacional.

Otro tipo de demanda, en cambio, acentúa la necesidad de transferencias sustanciales de recursos hacia los países subdesarrollados, o reafirman la soberanía nacional solore los recursos naturales y $\mathrm{cl}$ derecho de expropiación de las inversiones extranjeras - poniendo en evidencia la opción por cl llamado "desarrollo autodependiente", o, más especificamente, por el carácter prioritario de la cooperación 
e integración económica entre los paises del Tercer Mundo. Estas demandas conllevan, por lo general, un cuestionamiento del modelo de desarrollo extrovertido. Se parte de una doble premisa: de desequilibrios considerados estructurales y de que el tipo de interdependencia existente entre Norte y Sur es la causat principal de la inequidad que reina en las relaciones económicas internacionales. Revertir esta situación exigiría una estrategia de desarrollo de largo plazo radicalmente distinta del "paradigma occidental"; así, cn lugar de sostener la intcgración en el "sistema occidental", se pone énfasis en la autodependencia ${ }^{1}$.

Convienc insistir en un punto: que en el programa oficial del Nor se percibe una transacción entre los distintos sectores de la sociedad intermacional para impulsar un nuevo programa de desarrollo; y que la misma resulta análoga a las que en muchos aspectos suelen operarse entre los distintos sectores sociales de una nación. El amplio espectro de posturas e intereses que desarrollan los protagonistas - desde los sectores dominantes a los más desfatvorecidos, pasando por los sectores medios dinámicos-, dota a la mencionada transacción de una vulnerabilidad esencial, determinando que el frágil equilibrio Iogrado se vea amenazado constantemente por los efectos de medidas que, partiendo de las dispares oportunidades y aspiraciones de cada pais, satisfarán los intereses de una parte en desmedro de los objetivos de la otra.

Ello no implica negar los aspectos positivos de la solidaridad, particularmente "intra-Sur"; no obstante, nuestro propósito es des. nudar las posiciones fundamentales y los intereses básicos de cada parte para analizar las perspectivas de realización del programa, y, sobre todo, identificar los flancos más débiles, es decir, aquellos donde es presumible advertir la posibilidad de una ruptura de la alianza.

Según nuestra hipótesis, tanto el Norte como el Sur tienen su propio esquema del orden cconómico internacional que regulará las relaciones entre ambos grupos de países y entre los países de cada grupo. Además, ese esquema no responde en forma consistente a las propucstas asentadas en los foros internacionales. De cste modo, desprovistos de sus aspectos retóricos o estrictamente coyunturales,

${ }^{1}$ Amuzfgak, JAhavian: "A requiem for the North-South Conference", en Foreign Affairs, octubre, 1977, pág. 142. 
los nuevos órdenes económicos internacionales del Norte y del Sur son básicamente opuestos y dificilmente complementarios.

Finalmente, dentro del bloque Sur juegan un rol especial las llamadas potencias internedias (la actual "clase media" de las naciones), cuya adhesión a los reclamos básicos de lat mayoria de los países del Tercer Mundo no alcanza a disimular las tendencias políticas y cconómicas que, en lo esencial, prefiguan una mayor afinidad con los objetivos y planteos del mundo desarrollado. Jodavia vale la analogía con la clase media dentro de la socicdad nacional, en particular cuando se analizan sus patrones usuales de comportamiento a partir de alianzas con sectores de intereses diversos.

Una aproximación atenta a las manilestaciones implicitas y explicitas de la posición del Norte permite trarar un diseño de los perfiles básicos del nucvo orden internacional que proyectati el mismo cstiaria fundado en los siguientes puntos:

- Funcionamiento sin distorsiones del sistema de mercado y libre comercio;

- Cooperación estable cutre los países desarrollatos;

- Relaciones entre el Norte y el Sur estructuradas en tormo al concepto de interdependencia;

- Estabilidad en los sistemas políticos de los paises subdesarrollados y apoyo a la instauración de regímenes del tipo "autoritario flexible";

- Facilidades para las inversiones extranjeras y el acceso de las empresas multinacionales a los nercados de los países subdesarrolla. dos;

- Transnacionalización creciente de la toma de decisiones y disminución paralela o delsilitamicnto del poder decisorio del Estado Nacional;

-División internacional del trabajo fundada on uma perjferia espe. cializada en la oferta de materias primas y productos agricolas pro. ducidos principalmente por empresas modernas de alta productividad.

Ahora bien, cuando se observan los principates postulaclos del programa del bloque Sur, surge una imagen considerablenente distinta;

- Alteración de ciertos mecanismos esenciales clel funcionamiento del sistema de mercado; 
- Fortalecimiento del poder de negociación de los países del Tercer Mundo;

- Autodependencia individual o colectiva de los países subdesarrollados;

-Democratización a nivel internacional y énfasis en la necesidad de redistribución de los recursos;

- Reafirmación de la soberanía sobre los recursos naturales y control nacional sobre las empresas multinacionales;

- Fortalecimiento del Estado Nacional;

-Modificación de la actual división internacional del trabajo entre centro y periferia, y subordinación del comercio exterior a la estrategia interna del desarrollo autodependiente.

A continuación procuraremos esclarecer e interrclacionar estos puntos con el objeto de descubrir las aspiraciones menos explícitas en la posición de cada grupo, para luego concentrar nuestra atención en las tendencias observables en los paiscs latinoamericanos, particularmente en los de mayor desarrollo relativo, y en el comportamiento que previsiblemente adoptarán frente al Nor.

\section{ENFOQUES DIVFRSOS}

Antes de entrar en el tratamiento de los temas específicos, conviene revisar las posiciones asumidas por los especialistas y políticos repre. sentativos de uno y otro grupo de países en relación con las propuestas de un nucvo orden cconómico internacional.

En cuanto al bloque del Norte, se perciben en líneas generales tres cnfoques distintos:

a) Posición moderada. Sostenida por los actuales detentadores del poder y la riqueza. Aunque poseen clara conciencia de la necesi. dad de realizar cambios en las relaciones Norte-Sur, procuran "administrarlos" (the managerial response) de modo que, sca el que fucre el nuevo orden emergente, continúen siendo dueños de la situación.

Además, privilegian el valor de la estabilidad y ponen el acento en las soluciones de tipo técnico, relegando al último plano las de tipo político y normativo. Asimismo, rechazan el orden basado en las "esferas de influencia" y enfatizan, frente al nuevo marco de cre- 
ciente interdependencia, la necesidad de una conciliación de ambas partes. Finalmente, consideran que el sistema de relaciones internacionales vigente es susceptible de cambios significativos y que la guerra es instancia última y árbitro de todo conflicto.

Posicioncs de este tipo son sostenidas, por cjemplo, en algunos trabajos del Banco Mundial, del Club de Roma, del Overseas Development Council, de la Brookings Institution y, principalmente, de la Comisión Trilateral.

El Banco Mundial fue una de las primeras instituciones que reconocieron la necesidad de hallar urgentemente una respuesta "controlada" a las transformaciones planteadas por el Sur. En este sentido, el cstudio Partners in Development, elaborado por la Comisión Pcarson en 1969, si bien reconocía que las legítimas demandas del mundo en desarrollo exigian reformas en cl comercio, las finanzas y las inversiones internacionales, el cumplimicnto de estos reclamos no debía significar un sacrificio de los intereses básicos del Norte"2.

La Comisión Trilatcral, por su parte, ha manifestado a través de sus máximos representantes que sus preocupaciones básicas son el crecimiento de la economía mundial y el establecimiento de mecanismos de cooperación cstable entre los países del Norte frente a las amenazas provenientes de:

- el mundo comunista (susceptible de ser "administrada" mediante arreglos de tipo militar y político):

- el Tercer Mundo (controlable por medio del otorgamiento de concesiones superficiales), y

- la profundización de la competencia entre los paises desarrollados (cuyo control presenta dificultades mayores que las del mundo comunista $y$ el Tercer Mundo) ${ }^{3}$.

La respuesta "administrada" a estos reclamos por un nuevo orden estaría asegurada en el caso de acordarse una concertación entre los países industrializados, en la que descmpeñarían un papel importante las empresas multinacionales.

En cuanto al Tercer Mundo, se intentaría llegar a un entendi-

Vcase Smith, Tony: "Changing configurations of power in North-South relations since 1945", International Organization, Standford, Standford University, 1977, vol. 1, pág. 6.

"Véase Falk, Richard A.: "Contending Approaches to World Order", en Journal of International Affairs, vol, 31, No 2, 1977, pág. 184. 
miento "cooptacionista" con los centros regionales de poder económico (Brasil, México, Venezuela, Argentina, Arabia Saudita, Nigeria, India e Indonesia) .

Los problemas mundiales de mayor envergadura scrian solucionados mediante cambios menores y graduales - que no alterarían la cstructura del poder mundial- y por la cooptación privilegiada de algunas potencias intermedias, que podrian convertirse en serias desafiantes de la dominación hegemónica ${ }^{4}$.

De los innumerables trabijos producidos por los miembros de este grupo, es posible deducir un listado de las proposiciones más importantes sustentadas en relación con el vofi:

- apoyo a sistemas generales de preferencias para las importaciones de manuficturas de trabajo intensivo provenientes del Tercer Mundo;

- oposición a la indexación y a la "cartelización";

- apoyo al establecimiento de "códigos de conducta" para la gestión de las empresas transnacionales, exigicndo como contrapartida el otorgamiento de garantias a la inversion;

- apoyo al mantenimiento de la ayuda cxterna a ciertos niveles mínimos y conscntimicnto para que las demandas del Sur encuentren mayor recepción en el HMI y otras agencias internacionales.

b) Posición conservadora. Rechaza la idea de un nuevo orden internacional, calificaindolo de poco realista $\mathrm{c}$ impracticable. Sostiene que el orklen actual es susceptible de ser mejorado mediante la adopción de mecanismos graduales que permitan la solución "paso a paso" y "caso por caso" de los reclamos existentes. Asimismo, y según las palal)ras de Jahangir Amuzegar, of rece a los países subdesarrollados más que un nuevo orden una sucrte de new deal 5 .

Finalmente, rechazan las tesis cconómicas "intervencionistas", apoyando en cambio las posturas "librecambistas" que implican, obvia. mente, el sistcma de mercado libre y la libre competencia.

Dentro de esta corriente, los sectores más reaccionarios exigen una contraofensiva del Norte para recstructurar el sistema internacional de postguerra y asegurar la defensa contra los eventuales avances del

"'éase Mendlovitz, Saul: "The Program of the Institute for World Order", en Joumal of International Affairs, op. cit., píg. 2612.

Anitercar, Jahiscir, op. cit., píg. 146. 
mundo comunista (presión por mayores gastos militares) y contra los reclamos igualitarios del Iercer Mundo.

Los argumentos más radicales de esta posición pertencén a los analistas P. I'. Bauer y I)aniel Moynihan - a través de artículos publicados en la revista nortcamericana Commentary- y a grupos como el Commillec on Present Danger. En el numero correspondiente al mes de marzo de 1975, Moynihan. en la revista mencionada, afirma: "I a econonía mundial no es lo suficientemente mala como para justificar las medidas propuestas (por el l'ercer Mundo), y es mucho peor de lo que en realidad debería ser en razón de las medidas que el Tercer Mundo ya ha tomado"ii.

c) Posición radical. be acuerdo con lo sostenido por estos sectores, el nuevo orden "constituye 111 instrumento llamado a hacer posible una revisión profunda de la actual estructura de las relaciones internacionales a partir de un análisis crítico de la propia sociedad industrial o postindustrial donde les corresponde vivir"i. Aceptan las posiciones teóricas y los reclamos del sur y reconocen la existencia de imperativos morales y humanitarios para establecer con el 'I'ercer Mundo relaciones internacionales mís justas, que reemplacen a las actuales. Estas, al haber sido impuestas por los países desarrollados, responden exclusivamente a sus intereses.

Apoyan esta posición los críticos e intelectuales de la nueva izquierda y algumos sectores políticoss.

También en el Sur es posible ielentificar posiciones diversas:

a) Posición radical. Atribuyc el actual sublesarrollo del Sur a la estructura de dominación impuesta por los páises centrales durante la etapa colonial y la posterior fase neocolonial. Plantea uma revisión completa del orden actual, postulatudo cambios que permitan bases más igualitariats en la redistribución de la riqueza y el poder. Rechaza el paradigma occidental en favor de un tipo de desarrollo basado en

"Citado por Smith, Tony, op. cit., pág. 6.

Tfifsias, Fvriqu: "La Cooperación Fomómica Internacional. Una visión desde América Latina", exposición realizacla en el Seminario sobre Areas Prioritarias de Investigacion: Ecomomia Intcruarional y Paises en Desarrollo, organizado por cirpl.AN, Santiago de Chile, 25, al 27 de mayo de 1978, mimeo, píg. 7.

"Al respecto, pueden consultarse los trabajos de Geoffey Barraclough: "Wealth and Power: The politics of food and oil" $y$ "The Haves and the Have-Nots", en The New York Review of Books, $7 / 8 / 1975$ y $13 / 5 / 1976$, respectivamente. 
las características nacionales y en la fuerza y capacidad creativa propia de cada país.

Esta posición presenta una gran diversidad de matices: posiciones extremas -separación total del sistema y disociación absoluta-, posiciones de confrontación parcial y otras que apoyan tesis de disociación diferenciada, entre las que cabe mencionar, por ser la más conocida, a la self-reliance (autodependencia), con sus dos variantes, la individual y la colectiva. Según esta última tesis, la comunidad nacional debe dirigirse al exterior sólo cuando el aporte extranjero resulta indispensable en una actividad precisa y bien determinada.

I.os argumentos esgrimidos parten de una comprobación empfrica: la historia demuestra que nadie da voluntariamente nada; por lo tanto, para introducir cambios en las relaciones Norte-Sur es imprescindible asumir actitudes militantes.

La corriente de la self-reliance tiene un paralelo reaccionario en el Norte: se trata del Project Independence or Western Disengagement, que, bajo el liderazgo de Nelson Rockefeller, propugna la separación del Norte con el objeto de mantener el crecimiento de la sociedad industrial y marginarla de los problemas relacionados con la creciente pobreza del resto del mundo.

b) Posición moderada. Tanto como en el Norte, existen en el Sur tendencias moderadas que si bien reconocen la injusticia de la actual estructura internacional, consideran que una interdependencia creciente entre ambos bloques permitirá -a través de negociaciones globales y temáticas- la identificación de intereses mutuos. Ello dará lugar a beneficios recíprocos y posibilitará una más justa distribución de la riqueza y el poder.

\section{Fortal.ecimiento o alteración DEI. SISTEMA}

Habiamos afirmado que uno de los elementos básicos del nuevo orden internacional, tal como cs percibido por los países del Norte, es el mantenimiento del sistema económico de mercado y el principio de libre comercio. Para evitar distorsiones, necesitan contar con la adhe. sión de los paises subdesarrollados, subrayando que el sistema -a pesar de ciertas ineficiencias actuales y, sobre todo, de acuerdo al modo como ha venido funcionando desde 1945- se reveló esencialmente apto para lograr altas tasas de crecimiento y el adecuado desenvolvimiento de las relaciones económicas internacionales.

En esta instancia el acento está puesto en los ajustes requeridos 
por el juego de los mecanismos de mercado para eliminar los desequilibrios evidentes. Desde esta perspectiva, estos desequilibrios e ineficiencias no se originan en el sistema como tal, sino en su funcionamiento precario. La idea subyacente es que el crecimiento sostenido en los países desarrollados es un prerrequisito includible para el desarrollo económico de los países subdesarrollados: ello permitirá elevar la demanda de bienes provenientes del Tercer $\mathbf{M}$ undo, dinamizando el sector exportador y permitiendo que los paises subdesarrollados accedin a los productos industrializados y a la tecnología adecuada obligados por su propio desarrollo interno. Estas posibilidades desaparecerían si los paises centrales sufrieran procesos de estancamiento o recesión.

La noción de desarrollo simultínco $e$ interdependiente ha sido ampliamente analizada y su tratamiento excede los límites de este trabajo. Sí interesa subrayar la profunda divergencia conceptual existente entre este planteo y la interpretación del desarrollo contenida en la posición del Sur frente al Nofi.

En la clase de orden mundial propuesto por los países avanzados no tienen cabida medidas que prohíban o restrinjan la entrada de capitales extranjeros, la formación de cartels de productores, la indexación del precio de las materias primas, etc., y que constituyen parte significativa del ideario de nuevo orden defendido por el Tercer Mundo.

Los principales estudios acerca de las políticas que deberían implementar los países desarrollados enfatizan la importancia de una defensa consistente del sistema de mercado, por una parte, y el logro de un compromiso de los países subdesarrollados con los principios esenciales del mismo, por la otra. En Estados Unidos, las políticas tendientes a poner en práctica estos fines sólo apoyan aquellos esquemas que se revelen capaces de:

- proporcionar un rápido crecimiento económico mediante una economía de mercado libre;

- no adoptar posiciones reticentes frente a la inversión privada extranjera; y

- no promover alianzas y políticas antiamericanistas (como, por ejemplo, la formación de "cartels", las expropiaciones de bienes de inversión extranjeros, etc.) ${ }^{9}$.

-Theberge, James D. y fontaine, Rogif W.: Latin Ametica Struggle for Pro. gress, Lexington, 1977, pág. 52. 
No obstante, en la actualidad estos principios no son observados de modo ortodoxo por los paises industrializados. Sus propios problemas de inflación y desempleo generan políticas proteccionistas cuyos efectos alcanzan de lleno a las economías de los paises subdesarrollados. El "libre comercio organizado" que propone Francia, por ejemplo, no es más que un modo de proteccionismo dirigido tanto contra los paises desarrollados -con industrias mís competitivas on sectores de alta tecnología- como contra los paises subdesarrollados, que cuentan con lat ventaja comparativa de sus bajos salarios ${ }^{11}$.

Los informes de la Comisión Trilateral destian que en ticmpos de escasez, inflación y disminución del ritmo de crecimicnto econó mico, crecen las presiones en favor de una politica nacionalista: neomercantilista; $y$, por otra parte que los sistemis politicos demo. cráticos son particularmente vulnerables a presiones provenientes de grupos industriales, regionales y de organizaciones sindicales, que ven perjudicados sus intereses por la competencia extranjerian".

Existe sin embargo. cierta convicción acerca de lat necesidad de revertir esa tendencia y facilitar la apertuma de la economía con d objeto de permitir una colocación más favorable de los productos provenientes del Iercer Mundo. En Estados Unidos, aun los sectores más reacios a considerar la posibilidad de modificar el orden internacional aceptan que un programa de accion que exprese los inte reses de largo plazo debe implicar:

- una apertura sustancial de su cconomía, y

- la remoción de las barreias comerciales y políticas que olsstaculizan la inversión privada en el exterior.

La oposición de los países centrales a cualquier medida que afecte los principios de libre intercambio, compctencia y división internacional del trabajo, alcanza y afecta más allá de las relaciones internacionales, el plano interno de los paises subdesitrollados. Así, se cali. fican de "dispendiosas"e "inhumanas" políticas tales como el establecimiento de monopolios estatales de exportación; la proliferación de la acción del Estado en las compañias de transporte, bancos o

${ }^{10}$ Véase Serfaty, Simon: "Conciliation and Confromtation: A Stratcegy for NorthSouth Negotiations", en Orbis, N2 1, 1978, pág. 115.

"Crozit:k, Micuer. y otros: "The crisis of democracy. Report (un the governability of democracies to the Trilateral Countries", New rork University Press, 1977, pág. 11. 
empresas industriales; la supresión de actividades comerciales privadas en favor de empresas estatales (incluidas las cooperativas con patrocinio oficial); la prohibición o restricción a la entrada de capitales privados extranjeros y las "politicas antieconómicas de sustitución de importaciones y controles de cambios" $1 "$.

En el caso de los países subdesatrollados está en juego el modelo de desarrollo; en este sentido. muchos de ellos están convencidos de que la operación de revertir el proceso de redistribución de los recursos debe ser encarado fuera de las reglas del mercado.

De acuerdo con un ya avanzado proceso de revisión de las opciones económicas, un gran número de países periféricos -entre cllos los más desfavorecidos- han cuestionado la eficacia de los mecanismos de mercado y el libre comercio, proponiendo alternativas de desarrollo más equitativo y armónico. Los postulados contenidos en el programa del NoEI reflejan los objetivos de la periferia: obtener cambios sustanciales en el funcionamiento de la economía internacional, incidiendo en el plano específico de la división internacional del trabajo.

Aunque las posiciones distan de ser homogéneas, subyace la idea común de que sólo a través de la implementación de estos cambios se evitará el ahondamiento de las inequidades actuales y la condena de los países del Tercer Mundo a permanecer dentro de un desarrollo periférico y en creciente dependenciat.

\section{Cooperación o confrontación}

Los países industrializados despliegan en la actualidad esfuerzos considerables para redefinir bases de cooperación mutual ello a los efectos de alejar el peligro de fricciones o rupturas que los deje en posición vulnerable frente a lits naciones del Tercer Mundo o del bloque comunista.

Los antiguos fundamentos de cooperación económica cntre los países centrales sufrieron en esta década el impacto desintegrante de acontecimientos como el "shock Nixon", en 1971, y el embargo del petróleo seguido de la cuadruplicación del precio de los hidrocarburos en 1973, de modo que se impone volver a alguna forma de cooperación estable, tal como había venido sucediendo desde la Segunda Guerra Mundial.

"Bauer, P. ' $\Gamma$. Y YAmry, B. S.: "Against the New International Economic Order", en Commentary, No 63, Ap. 77, pág. 28. 
Por otra parte, la redistribución del poder mundial y el reacomodamiento derivado de la "détente" acentuaron dramáticamente las diferencias entre los distintos miembros de la alianza occidental tanto en el plano militar como en el político y cconómico. Influyentes círculos de poder consideran, dentro del marco de los países desarrollados, que "el plano visible de la escena internacional está más dominado por el conflicto entre el mundo trilateral y $\mathrm{cl}$ mundo en desarrollo que por el conflicto entre las democracias trilaterales y los Estados comunistas, y que las nuevas aspiraciones de los países del Tercer Mundo representan en conjunto una amenaza mucho mayor a la naturaleza del sistema internacional..."13. Resulta por lo tanto natural que, dentro de la estrategia del Norte, consolidar el bloque de los paises desarrollados sea el elemento clave para afrontar en mejores condiciones las presiones del Sur. Dentro de este esquema Estados Unidos debe cumplir un rol fundamental, tanto por el hecho -como explica Kissinger- de que sus intereses cstán más en la estructura global del orden que en la administración de cualquier empresa regional, como por la circunstancia, también destacada por Kissinger esta vez ante la unctan, en mayo de 1974: que Estados Unidos, a diferencia de otros países desarrollados, pucde resistir la confrontación e ignorar propuestas "no realistas" y "demandas perentorias". Europa Occidental no saldría tan fácilmente inmune de una confrontación con los países de la OPlP, por ejemplo, y en consecuencia es más proclive a buscar vias de entendimiento con el Tcrcer Mundo que, en muchos casos, desbordan los parámetros "realistas" sostenidos por los norteamericanos.

De este modo, restablecer la confianza y la estabilidad de las relaciones con sus socios occidentales atendiendo a la diversidad de situaciones, al surgimiento de una renovada unidad europea sobre la base del predominio germano occidental, y al logro de una nueva cooperación atlántica bajo la dirección americana, resulta de interés prioritario para Estados Unidos ${ }^{14}$.

Precisamente, el objetivo básico del esfuerzo de la Comisión Tri. lateral es minimizar las fricciones y la competencia dentro del mundo trilateral, unificándolo a lia mayor brevedad.

Otro elemento que favorece la estrategia del Norte es la evolución de las relaciones comerciales entre los países del bloque. En este

"BrzeZinski, Zbigniew: "Trialogue", Summer 75, pág. 12.

"Serfaty, Simon: op. cit., pág. 112. 
sentido, el comercio entre países industrializados y con estructuras similares resulta mucho más dinámico que el intercambio entre países de desarrollo desigual.

Existe en la actualidad, además, un nuevo modo de interdependencia entre los países industrializados de Occidente, derivada de la especialización intraindustrial. Los países subdesarrollados deberán tener muy en cuenta esta circunstancia. "El espíritu de Rambouillet" -como dice Furtado-, debilitará la posición de los países periféricos. "La emergencia de un sistema de corresponsabilidad de las grancles potencias en la gestión de la economía internacional debilitará la posición de los países periféricos necesariamente"15.

Este primer objetivo del nuevo orden mundial, tal como resulta planteado por los páses industrializados, resulta conflictivo en relación con las aspiraciones del Tercer Mundo. En el anverso del mismo estaría el declarado propósito de los paises subdesarrollados de fortalecer su poder de negociación y afianzar la solidaridad entre sí, con el objeto de constituir un bloque sólido frente al Norte.

Si bien es cierto que los reclamos del Tercer Mundo en relación con el establecimiento de un nuevo orden internacional son anteriores a la crisis del petróleo, y que en muchos casos no son más que la revalorización de antiguas demandas detectables a partir de la década del $60^{16}$, debe reconocerse que el fulgurante éxito de la OPEP en 1973 fue un ejemplo alentador y un factor aglutinante para los países subdesarrollados. I a firme y espontánea solidaridad alcanzada por los exportadores de petróleo no pudo ser fracturada ni siquiera por la evidencia de que los logros de la opf.p constituían serios reveses para los planes de desarrollo de los países más pobres.

El prolongado y decepcionante Diálogo Norte-Sur llevado a efecto en París fue un test fundamental para poner a prueba esta solida. ridad; y aunque se idealizaron las posibilidades de una acción similar en relación con otras materias primas, el resultado fue la toma de conciencia del poder potencial de los paises productores en el plano internacional. Por su parte, los países desarrollados trataron por todos los medios de erosionar esa cohesión, subrayando los enor. mes perjuicios que sufrirían las naciones más débiles y la imposibilidad de transferir la experiencia de la DPEP a los productores de

"Furtado, Celso: "El reordenamiento de la economia mundial", en Carter y la lógica del imperialismo, San José. Hugo Assmann, ed., 1978, pág. 304.

nPrebisch, Raúl: Hacia una nueva polltica comercial para el desarrollo, unc. TAD, 1964. 
otras materias primas (salvo, quizá, la bauxita, el estaño y en menor medida el cobre y el manganeso), y desagregando además, a los países exportadores de petróleo del Tercer Mundo, al extremo de hacerlos corresponsables de la suerte del llamado Cuarto Mundo (así, se los puso en pie de igualdad con las potencias industriales como posible fuente de ayuda para los países más pobres, a pesar de la enorme desproporción entre el Producto Bruto Nacional combinado de uno y otro grupo) ${ }^{17}$.

Sin embargo, cabe consignar que parte del poder derivado del petróleo pudo ser usado efectivamente para influir sobre los aspectos económicos de interés más gencral en el conjunto de los países sub. desarrollados -como sucedió en el Diálogo de París-, y en tal sentido constiuyó un elemento esencial en el aumento del poder económico $\mathrm{y}$, por lo tanto, de negociación de la periferia.

En síntesis, si los paises del Norte, al mismo tiempo que reconocen la necesidad de un orden mis justo y cquitativo - con mayores oportunidades para los de menores recursos- se esfuerzan por consolidar su cohesión como bloque, los paises del Sur tratan, por su lado, de incrementar su poder de confrontación con el objeto de arribar a las posteriores negociaciones en condiciones mís ventajosas. Y si bien los foros multitudinarios - como la Asamblea General de la NU - no son los más indicados para lograr resultados concretos en materias tan complejas, permiten exteriorizar esa solidaridad.

La confrontación, a pesar de ser una alternativa poco deseable, constituye siempre un camino para el logro de objetivos específicos. Utilizando la analogia de Sidney Weintraub, un sindicato no obtiene concesiones por medio de imploraciones sino por el ejercicio de su poder $^{18}$.

\section{INTERIEPENDENCIA O AUTODEPENDENGIA}

Ya nos referimos a la creciente interdependencia de las sociedades centrales. Una interdependencia de otro tipo es la que se postula para los países desarrollados y subdesarrollados en el marco global de la evolución del sistema capitalista.

"TiTrilaterat, Commission. Task Force Reports 1-7. The Triangle Papers: 3: "A turning point in North-South Economic Relations", por Richard Gardner, Saburo Okita y B. J. Udink, en New York University Press, 1977, pág. 61.

${ }^{19}$ Weintraub, Sidney: "Nort-South Dialogue at the UN. How the uN votes on Economic Issues", en International Affairs, vol. 53, Ap. 77, No 2, pág. 199. 
En el actual contexto de las relaciones internacionales no resulta demasiado evidente la posibilidad de una vinculación realmente interdependiente entre las economías subdesarrolladas y dependientes del Sur y las economías desarrolladas y autocentradas del Norte. No obstante, de acuerdo a la opinión de ciertos sectores provistos de poder significativo tanto del mundo industrializado como del Tercer Mundo, esta interdependencia es el único camino capaz de evitar la amenaza de confrontaciones entre el Norte y el Sur. "Los países subdesarrollados necesitan ayuda, tecnología, Know-how y mercados de los países trilaterales, y los países trilaterales necesitan a los países subdesarrollados como fuentes de materias primas, como mercados de exportación y como socios constructivos"10, señala un informe de la Trilateral Commission en una frase que resume el fundamento cxplícito del énfasis en la relación interdcpendiente y se inserta en el ya aludido marco teórico del "desarrollo simultáneo" de centro y periferia. No resulta demasiado claro, por otra parte, que el programa del Nofi implique una reducción sustancial de esta interdependencia asimétrica, ya que el catálogo de reivindicaciones contenidas en el mismo se incluyen postulados que suponen la búsqueda efectiva de nucvas formas de cooperación horizontal y de un modelo de desarrollo autodependiente, junto con otros que evidencian el interés por una mejor y más completa inserción en el sistema mundial, que podrían llegar a reforzar -en el caso de que sea lograda- los lazos que unen el mundo industrializado con el subdesarrollado.

No obstante, los paises del Norte advierten en el programa del NofI cierta tendencia a minimizar la dependencia recíproca entre Norte y Sur, y llaman la atención sobre los peligros que ello acarrcaría para Ia estabilidad del sistema. En este sentido, están de acuerdo en la necesidad de dar satisfacción a ciertos reclamos de los paises subdesarrollados, con el objeto de que las relaciones de interdependencia postuladas reflejan en alguna medida los intereses de los mismos.

Si bien es cierto que existe dependencia recíproca entre el mundo desarrollado y el subdesarrollado, es igualmente innegable que un extremo de la relación resulta mucho más dependiente que el otro de los resultados de la interdependencia. El Sur es significativo para

"Trilateral. Commission, op. cit., pilg. 59. 
el Norte como mercado para sus exportaciones y éste es un aspecto que presenta en todos los análisis que tratan el tema. Además de su importancia cuantitativa, los mercados del Tercer Mundo posibilitan en muchos casos -como un factor importante entre otros- la expansión de sectores industriales que en los países desarrollados soportan etapas de desaceleración. Es el caso típico de la industria nuclear alemana, que en 1975 atravesaba problemas de desempleo y existían síntomas que hacían presagiar el cierre de algunas fábricas. Así, Alemania se veía enfrentada a la posibilidad de perder el esfuerzo económico y tecnológico realizado durante varios años, con el agravante de verse obligada a abandonar la esperanza de que ciertas innovaciones tecnológicas pudiesen reactivar en el futuro esta rama industrial. En esas circunstancias, cuando mantener aglutinadas las inversiones en el área atómica requerían un esfuerzo mayor, el contrato con Brasil le permitió contar con los 10 ó 15 años que necesitaba. Brasil soportó hasta cierto punto los costos de desenvolvimiento de los nuevos reactores, posibilitando que la industria nuclear germana permaneciese viva y en pleno funcionamiento.

Asimismo, los países del Sur son importantes como proveedores de materias primas, y fue justamente este aspecto el que sensibilizó a los países industrializados frente al problema de la interdependencia. Ya se mencionó, sin embargo, que el intercambio entre los países centrales tiende a aumentar en detrimento del existente entre países centrales y periféricos. Estos últimos, a su vez - con una participación cada vez menor en el comercio mundial (del $30,5 \%$ en 1950 , al 24,6\% en 1976 según datos del Banco Mundial) - realizan la mayor parte de sus transacciones no entre sí, sino con el mundo industria. lizado.

La consecuente vulnerabilidad se ve agravada por un cambio de perfil en Ia demanda mundial, que paulatinamente va descolocando la oferta proveniente de los países subdesarrollados.

Ia interdependencia, para ser tal, supone una simetria entre las partes, que no se da en el caso Norte-Sur y que resultará ilusoria si la especialización de la periferia mantienc sus características actuales.

El programa del NoEI no cuestiona globalmente el concepto de interdependencia propuesto por el Norte, y en muchos casos lo sostiene y aun lo defiende como una vía para hacer valer su reforzada capacidad de negociación; sin embargo, traduce al mis- 
mo tiempo la voluntad de analizar otras alternativas. F.l tema de la self-reliance colectiva ha ganaclo espacio entre los paises del Tercer Mundo, y a su luz es posible considerar con sentido renovador la problemática integracionista, las ventajas de una intensificación de vínculos entre los países suldesarrollados - a nivel regional, subregional o global-, la formación de empresas transnacionalcs cntre países subdesarrollados, etc.

No se trata de una tendencia autírquica o de "retiro" del sistema. El acento está puesto en la valorización de los recursos propios como garantía para el logro de un desarrollo por vías no condicionadas por la cstrategia antagónica de los países industrializados.

El futuro orden internacional tendrí un perfil en caso de predominar la opción "interdependentista", y otro considerablemente distinto si la que prevalece es la alternativa "autodependentista".

\section{Democracia O avtoritaris.ho}

Los aspectos más complejos del programa de cambio del orden internacional se agrupan en torno a los presupuestos políticos implicitos en los distintos modelos que se propician.

El modo ambiguo y general con que se han tratado los temas estrictamente politicos se agrava cuando se comprueba que, en muchos casos, resulta imposible inferir con claridad la perspectiva ideológica de la cual se parte. Ello hizo posible que se atribuyeran al programa del NoEI distintos y dispares objetivos que van desde la implantación de una suerte de socialdemocracia global, hasta el afianzamiento del totalitarismo gubernamental o la difusión del socialismo.

Conclusiones tan disfmiles obedecen en parte a la defensa de intereses determinados (presentar al xori como el emisario de una grave amenaza, o, por el contrario, como el marco de referencia necesario para llevar a la práctica los ideales de justicia y desarro. llo); sin embargo, son generalmente el resultado de planteos equívocos y de reservas mentales en el caso del Norte, y del divorcio entre aspiraciones y realidades y tendencias en el caso del Sur.

En nuestra opinión, el análisis de los presupuestos políticos del nuevo orden debería alsarcar cuatro planos distintos.

En cuanto a la posición observable en el Norte -que en este punto corresponde casi exclusivamente a la de Estados Unidos, es necesario diferenciar el plano de lis posiciones declaradas del plano 
correspondiente al orden descado (esto es, scparar la retórica del proyecto político subyacente).

En relación con los países del Sur, corresponde distinguir el plano de las aspiraciones políticas bísicas -que registra diferencias sustanciales entre los países-, del plano de las tendencias actuales (con escasos puntos en comb́n con liss aspiraciones originarias). El cstudio de estos aspectos deberia develat los puntos de contacto y de friccion entre las tendencias manifiestas y los propósitos subyacentes de ambos bloques.

Así, el análisis de la posición declarada por Estados Unidos en cuanto al substrato político del nuevo orden internacional lleva a ciertas conclusiones confusas.

Parce obvio que an nuevo orden ecomómico internatrional no puede adquirir significación plena si no va acompañado de un nucro orden interno coherente con sus premisas búsicas. Esta afirmación no debe, sin embargo, arrastrarnos a la falacia de pretender primero una más justat y equitativa estructuma interna y lecgo da modilicación del orden internacional, como si se tmatara de variables independientes.

De las declataciones, estudios académicos y proposiciones significativats originatas en Estados Unidos, parece desprenderse que el paradigma propucsto a los paises del Tercer Mundo es el ideal democrítico. De acuerdo con la misma fuente, se tratióí de la vía más adecuarda para aumentar el bienestar de todos los sectores sociales en forma amónica, señalíndose, al mismo tiempo, que "una estructura social en la cual la riqueza y el saber estín concentrados en las manos de unos pocos, no conduciría a la democracia"20. Es decir, que democratización y más amplia y justa distribución de los recursos son términos interrchacionados de un proyecto político que se propondría a los países del Tercer Mundo.

Sin combargo, en muestra opinión el acento se ha colocado en un aspecto menos declarado pero más importante para los paises centrales: la estabilidad política del mundo subdesarrollado.

Este es, en sumit, el objetivo subyacente bajo todos los postulados. Y si reducir las desigualdades de los ingresos es importante, lo es fundamentalmente porque contribuye a aumentar la estabilidad política. "Comparar seguridad contra la inestabilidad política mundial y otros desatrollos indescados puede ser un motivo para transferir recursos", afirma Richard Cooper, reflejando la posición de la Tri-

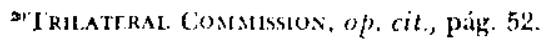


lateral, una entidad cuya alta cuota de poder e influencia es bien conocida²1.

La actual situación política de Inán demuestra que el simple crecimiento económico no asegura la estabilidad política; por ello, es necesario identificar aquellos elementos aptos para el logro de ese primordial objetivo.

La primera confusión surge cuando se compara la declarada defensa del sistema democrático, por una parte, y la tan mentada redistribución interna de los recursos, por la otra, con los ejemplos propuestos como modelos posibles: Brasil, Venezuela, México, Taiwán, Hong Kong, Singapux, Malasia.

Un país como Brasil, con su sistema politico autoritaio, que ha optado por un tipo de desarrollo que implica la concentración elitaria del ingreso, suele ser considerado un patradigma. I a mayoría de los analistats norteanericanos coincide en alimar que sólo Brasil, entre las potencias intermedias latinoamericanas, ticne la oportunidad de elevarse a la categoria de potencia secundaria en Ias próximas décadas. Como mérito relevante se señala la estabilidad política lograda por la élite militar y civil que gobierna el país desde 1964 , 'comparándola con la inestabilidad que la caracterizado a otros paises medianos (entre ellos, la Argentina).

Según Theberge y Fontaine se trata de una élite calificada capaz de poner en práctica un programa de efectivas reformas, y orientada por el cúmulo de sus experiencias a creer en el gobierno fuerte y la empresa privada como las llaves miestaras del desarrollo económico 22 .

"Hay muchos ejemplos de páses del lercer Mundo - dicen Bauer y Yamey- que han crecido rápidamente, como Corea del Sur, Taiwán, Hong Kong, Malasia, Costa de Marfil, Kenya, los Estados petroleros de Medio Oriente, Brasil, México y Venezuela"'w.

$¿$ Cómo conciliar entonces los modelos que se ofrecen con los principios defendidos? ¿Cómo compatibilizar un desarrollo conómico centrado en $\mathrm{cl}$ papel de la gran cmpresa privada, nacional y extranjera -que produce para sectores restringidos del mercado interno- con una distribución más equitativa de los recursos? Si éstos deben con. centrarse en los sectores más dinámicos y sofisticádos y de acuerdo

\footnotetext{
"Cooper, Richard: "New International Fonomic Order for Mutual Gain", en Foreign Policy, No 26, Spr. 77, pág. 66.

"Vease Theberge y Fontaine, of. cit., paig. 41.

solbidem, paig. 26.
} 
a las pautas señaladas por las empresas transnacionales -caso flagrante en los países de Asia Oriental-. ¿Cómo evitar el detrimento de la agricultura y la industria pequeña y mediana, que producen para el mercado interno?

El tipo de desarrollo propuesto exige mantener un nivel de concentración de la renta incompatible con los postulados de mayor equidad. En este sentido, la experiencia del Brasil -reconocida por sus propias autoridades ${ }^{24}$ y reflejada con exactitud en los últimos informes del BIRF ${ }^{25}$ - es un ejemplo del carácter contradictorio de los términos y modelos utilizados.

Por otra parte, la democracia implica participación popular, movilización politica y masas politizadas, que los sectores del Norte consideran más una amenaza que un desideratum. En relación con la gobernabilidad de una sociedad, una población politizada puede constituir un problema de envergadura en las sociedades de des. arrollo tardío.

¿Cuál es el modo, entonces, de asegurar la solidez y perdurabilidad del sistema político? Parece claro que las reglas del juego democrático no son, en la perspectiva de Estados Unidos, totalmente adecuadas para lograrlo. $\mathrm{Al}$ menos, quienes desde el Norte pretenden responder a esta interrogante han planteado serias dudas en relación con la aptitud del sistema democrático para llevar a la práctica ese objetivo. El proyecto que estimulan - transmitido y reproducido por las élites de los países subdesarrollados--, tiene las características de un régimen que podría describirse como "autoritario flexible", a mitad de camino entre la dictadura tradicional y la democracia liberal, que en los países periféricos se han revelado ineficaces para preservar la estabilidad del sistema.

Las características esenciales de los regímenes de tipo "autoritario flexible" serian:

-Concentración del poder real en una élite tecno-burocrática, civil o militar.

-Sólido compromiso con el modelo de desarrollo económico basado en la actividad de la gran empresa privada, nacional y extranjera, y en el papel clave del sector exportador.

\footnotetext{
rVéanse los conceptos vertidos por el ex ministro de Hacienda y futuro ministro de Agricultura, Delfim Netto, en conferencia transcripto por el Jornal do Brasil, 17/10/1978, pág. 17.

ÆVéase Jornal do Brasil, 22/10/1978, pág. 36/38.
} 
-Bloqueo de los canales de participación popular.

-Liberalización controlada capaz de reducir las tensiones provenientes de la falta de participación, ello sin que se promuevan en forma simultánea aperturas democráticas efectivas.

- Aplicación de mecanismos de control sobre las instituciones básicas del sistema para permitirles un juego reducido, sin comprometer los fundamentos del régimen.

Conviene señalar la diferencia que existe entre la gradual liberalización -aceptada como una característica del régimen-, y la democratización que se posterga para una etapa muy posterior. Este es el planteo teórico sostenido entre otros por Juan Linz, de reconocida influencia sobre importantes sectores de poder en Brasil (en especial sobre Golbery da Couto e Silva y Ernesto Geisel), que distingue las medidas que tienden a disminuir la represión, conceder más libertad de palabra y de crítica y respetar en mayor grado los derechos y garantías individuales (liberalizadoras), de aquellas que se refieren específicamente a elecciones, entrega del poder a los elegidos, participación popular, etc. (democratizadoras).

El método de liberalizar sin producir al mismo tiempo avances democráticos conduce a un régimen autoritario no rígido, que algunos han dado en llamar "dictadura benigna".

En cuanto a la posición de los países subdesarrollados, todos sus reclamos se dirigen al logro de un sistema democrático internacional que les permita una participación acorde con el mayor peso que han adquirido. Sin embargo, esta democratización reclamada no se corresponde con los sistemas políticos internos, factor que sirve a los scctores más conservadores del Norte para referirse al "cinismo" que caracterizaría las demandas de una "nueva ética" en el plano internacional, presupuesta por el NoFI.

La explicación del desfasaje entre aspiraciones igualitarias y de. mocráticas en el plano externo y tendencias autoritarias y discriminatorias en el interno, debe pasar por el análisis de la estructura sociopolítica y económica de los países del Tercer Mundo como un factor limitativo de sus alternativas.

La tendencia a implantar modelos "estatizantes", con el sector público ocupando el papel protagónico, es muy marcada en los países de menor desarrollo relativo e independencia reciente. Asimismo, se advierte cierto deslizamiento hacia formas de capitalismo de Estado, con distintos grados de profundidad según los casos. 
Este último aspecto debe ser relacionado con las características de la estructura social. I a ausencia o debilidad de las burguesías empresarias locales da lugar a un tipo de sociedad que Samir Amin calificó de "truncil" 26 , donde el papel de liderar el proceso de desarrollo nacional es ocupado por el Estado, percilsido con el único poder capaz de poner límites a la dominación extranjera y dirigir el proceso de crecimiento para beneficio de todos los sectores.

Surge así una burocracia estatal de dimensiones y características que no reconocen antecedentes: actúa de acuerdo a un programa propio, no responde a los intereses de ningún grupo social en particular ni está sujeta a presiones internas, lo que la diferencia tajantemente de las burocracias de los países desarrollados ${ }^{27}$.

También en los países de mayor desarrollo relativo, donde existe un Estado claramente consolidado y un sector burgués fuerte, se advicrte una revalorización cíclica de las opciones estatistas. Ello se explica porque la burguesía, en razón de sus estrechos vínculos con el capital internacional y los sectores tradicionales -latifundistas o vinculados con el comercio extcrior-, se ha revelado incapaz de ser el motor de un desarrollo autocentrado. Tampoco ha podido imponer un proyecto propio a toda la sociedad, como lo hiciera la oligarquía en su momento. Esta debilidad, que no se atenúa con su crecimiento, determinó que fuese el Estado quien tomara en sus manos la conducción del proceso de desarrollo cuando entró en crisis el modelo de "crecimiento hacia afuera".

Las alternativas "estatistas" están siempre presentes. Puestas en práctica por gobiernos de muy distinto signo, denostadas por los regímencs liberales, no llegan a agotarse ni se realizan plenamente. En este sentido, han merecido el destino común de la mayoría de las opciones intentadas en los últimos cuarenta años.

\section{INTRODUCGION AL CASO LATINOAMERICANO}

Si bien hasta aquí hemos cncarado en forma global las posiciones de los países desarrollados y subdesarrollados en relación con los principios esenciales del nuevo orden económico internacional, creemos imprescindible aludir a las importantes diferencias existentes dentro de cadla gxupo. Estas diferencias determinan la adopción de actitudes diversas no sólo frente a la estructura deseable del nuevo

2"SMin, Samir: Ite development ine'gnl, París. E. de Minuit, 1979, pág. 175.

silbídem, pág. 302. 
orden emergente, sino también respecto a cuál es el tipo de vinculación que se pretende con el mismo.

A pesar de las divergencias, algunas de las cuales yat fueron senaladas, los países del Norte gozan de mayor homogencidad. Sus enfrentamicntos - por cjemplo, las distintas posiciones obscrvalbles entre países como Alemania, Francia o Estados Unidos- son menos evidentes en la prácticat que en el tenor de las declaraciones.

Entre los países del Sur, en cambio, la heterogeneidad es considerable, tanto si se atiende a los niveles de desarrollo alcanzado como si se toman en cuenta los recursos naturales propios y el grado de madure\% de sus respectivos sistemas políticos.

En la actualidad resulta casi tradicional distinguir, dentro de los países subdesarrollados: a) los exportadores de petróleo; b) aquellos que sin serlo poseen otros recursos valiosos y uma cstructura productiva aceptablemente diversificada; y c) los países que carecen tanto de petróleo como de otros recursos valiosos.

E1 punto c) agrupa a la mayor parte de la población mundial, constituida en lo que se ha dado en llamar el Cuarto Mundo.

América Latina, por su parte, constituye un ejemplo representativo de la diversidad de situaciones existentes en el Sur.

Resultat por lo tanto previsible que los paises del Tercer Mundo -tomando esta denominación en sus implicaciones más generales y sin subestimar la soliclaridad alcanzada en torno a las premisas básicas ya descriptas-- adoptarán en el luturo comportamicntos diferenciados.

Nos interesa indagar especialmente en la acción previsible de los paises intermedios; en ellos convergen algunas características propias de los desarrollatlos junto con los rasgos típicos del subdesarrollo. Esta particularidad les plantea una opción difícil: o consolidan sus vinculos con el resto del Tercer Munclo y contribuyen activamente a implementar una estrategia común con los demás países subdesa. rrollados o, marcando las distancias que los separa de éstos se esfuerzan por logiar una incorporación -aunque sea subalterna- al cerrado circulo de los patises industrializados de Occidente.

El caso latinoamericano ofrece varios cjemplos de países intermedios: Brasil, Argentina, Venezucla, México, Chile, Colombia. En primer lugar, procuraremos señalar las tendencias predominantes en los últimos años, especialmente en el plano político, y luego fijar la posición que a nuestro juicio es factible que adopten frente al nuevo orden internacional. 
Tendencias observables en América Latina

No se nos escapa que el análisis de las tendencias observables en los últimos años en América Latina exige una exposición minuciosa y un trabajo complementario que refleje las alternativas del Norte. A modo de cnsayo, trataremos de avanzar señalando los grandes rasgos predominantes, convencidos de que nuestras omisiones y errores servirán para estimular la discusión y enriquecer la investigación posterior.

Por su carácter periférico, el desarrollo latinoamericano estuvo siempre condicionado por la evolución que registraban las relaciones internacionales y el sistema capitalista mundial. Lo distintivo de los últimos trcinta años sería - de acuerdo con el análisis de Sunkel y Fuenzalida- la aparición de un nuevo tipo de sistema global originado por la expansión del capitalismo oligopólico tecno-industrial, el cual, en su nueva etapa de organización transnacional, ha marcado de un modo que no tiene precedentes el desarrollo político, económico, cultural y social de la región ${ }^{28}$.

En esta fase, el avance registrado por el capitalismo -fundamentalmente a través de empresas transnacionales e instituciones conexas- ha acrecentado y dado nuevos matices a una de las características estructurales del subdesarrollo de América Latina: la desnacionalización cconómica y cultural ${ }^{29}$.

Se observa asimismo que los importantes éxitos alcanzados en la economía de la región durante los últimos treinta años no han impedido el afianzamicnto de un tipo de desarrollo excluyente, concentrado y conflictivo ${ }^{30}$. Excluyente, porque niega posibilidades de participación a casi el $35 \%$ de la población, contribuyendo a perpetuar otra de las caracteristicas estructurales del subdesarrollo latinoamericano: la marginalidad. Concentrado, porque los patrones de distribución del ingreso no han variado, aunque se observa un

"Sunkel, Osvajto y Funnzalida, Eumundo: "Capitalismo Transnacional y Desarrollo Nacional", documento de apoyo presentado en el Seminario América Latina y el Nofi, Viña del Mar, 7 al 11 de enero de 1978. Serie Documentos de Trabajo CPU, No 143, pág. 5.

${ }^{20}$ Véase la importante obra de Helio Jaguaribe, Crisis y alternativas de América Latina: Reforma o Revolución, Paidós, Buenos Aires, 1972, especialmente págs. 21 a 39 .

"PrfBisch, RAúl: "Planificación, Desarrollo y Democracia", ponencia presentada en la Conferencia Regional sobre Condiciones sociales de la democracia, cr.Acso, San José de Costa Rica, 16 al 20 de octubre de 1978, mimeo., pág. 1. 
tipo elitario (predominante en Brasil y Chile) y otro mesocrático (en Venezuela, México y Costa Rica) ${ }^{31}$. Conflictivo, por la creciente pugna distributiva que gencra: las pautas de consumo de los sectores privilegiados resultan incompatibles con la integración social de las mayorías y consecuentemente con el avance de la democracia de masas ${ }^{32}$.

La permanencia de estas tendencias pone de manifiesto el carácter centrípeto del capitalismo y desvanece definitivamente el mito de que "...el desarrollo periférico, a imagen y semejanza del desarrollo en los centros, traería la difusión progresiva del bienestar, así como el avance y la consolidación de los movimientos democráticos"33.

En torno a la idea difusionista del desarrollo resulta útil destacar que se halla de alguna manera presente en el programa oficial del NOEI. De acuerdo con sus lineamientos, el modelo actuaría más o menos de este modo: el Norte deberia mantencr el funcionamiento dinámico de su economia a fin de consumir en forma creciente los bienes provenientes del Sur, pagarlos mejor (para ello se implementaría el sistema de indexación de precios y se pondrían en práctica sistemas de garantías, etc.), y transferir capitales y tecnologia. A lo largo de este proceso, el desarrollo se iría "derramando" hacia el Sur, donde las élites gobernantes del mundo en desarrollo se encargarían de transmitirlo hacia sus respectivas periferias.

En cuanto a América Latina, la nueva fase de desarrollo del capitalismo ha dado lugar -contrariamente a lo sustentado por las tesis difusionistas - a una creciente polarización, tanto a nivel internacional como en el plano interno, hecho que a su vez afecta las relaciones entre el Estado-nación y el capitalismo transnacional ${ }^{34}$.

En efecto, la internacionalización de la estructura productiva -que trasciende los límites territoriales que el Estado pretende acotar-, junto con el tipo de crecimiento desigual y las agudas tensiones existentes entre los sectores hegemónicos (nacionales e internacio. nales) y los grupos marginados de los beneficios del proceso, han puesto en crisis la estructura del Estado, dejando abierto el camino

\footnotetext{
"Véase Graciarena, Jorge: "Tipos de concentración del ingreso y estilos políticos en América Latina", en Revista de la CFPAL, 1976, segundo semestre.

"Prebisch, Raúl: "Exposición en la ocir:", en La Opinión, Buenos Aires, 14 de diciembre de 1978.

sPrebisch, Raúl, op. cil., pág. 2.

"Sunkei., Osvaldo y Flenzal.jda, Edmlendo, op. cit., pág. 28.
} 
para las soluciones de fuerza y reduciendo en forma considerable las posibilidades de funcionamiento del sistema democrático con participación popular.

Surge entonces una de las tendencias claves de la región: regimenes políticos de tipo autoritario flexible, autocraciats de nuevo cuño distinta de las tradicionales (Stroessner, Somoza) y de los populismos clásicos (Vargas, Perón, Pérez Jiméne\%, Rojas Pinilla).

Conviene tener en cuenta que la tendencia anotada se refiere no tanto a los gobiernos vigentes, sino al tipo de régimen que ocupará a nuestro juicio el espacio político regional de los próximos dicz. años. Dentro del mismo incluimos todas las lormas de dominación propugnadas por el Norte y compartidas por las élites tecno-burocráticas latinoamericanas que privilegian la estabilidad y eficiencia del sistema y no exigen necesariamente que el poder politico formal permanezca en manos de las fuerzas armadas. Los autoritarismos flexibles también pueden darse en sistemas que, bajo formas de: apariencia democrítica, implanten controles o limitaciones que cicrren los mecanismos de acceso popular a la participación politica.

El régimen descripto parece adecuarse a la nueva estructura del sistema global, en lo que podría calificarse de "afinidad clectiva" 3. entre el autoritarismo flexible y el capitalismo oligopólico tecnoindustrial.

Finalmente, tres notas ayudarán a precisar los supuestos consignados:

1. El sentido de la dominarion. En el estudio de este tomat deberán distinguirse las formas del Estado autoritario -que presentan grandes similitudes en la región- con el sentido de esa doninación, que exige el análisis de la base social y la orientación de las políticas implementadas. Ello permitirá diferenciar, por ejemplo el autoritarismo brasileño del peruano (Velazco Alvarado) o del boliviano (Torres) ${ }^{36}$.

2. El sentido de la oposición clísica entre democracia y autorita. rismo. De acuerdo al tipo de clesarrollo, de consumo privilegiado,

${ }^{25}$ Esta denominación fue introducitla por Fernando Henrique Cárdoso y Enzo Faletto en su ya clásica obra: Dependencia y Desarrollo en América Latina, Siglo xxı, Bucnos Aires, 1969.

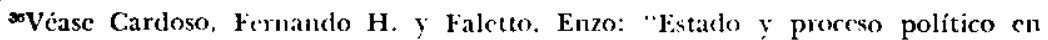
América Latina" en Revisfa Mexicana de Sociologia $N^{\circ} 2$, 1977, en especial, pún. 373 a 387. 
vigente en la región; al grado de cultura política alcanzado (sobre todo en los paises mayores) y al exceso de demandas insatisfechas, pareceria imposible mantener las reglas del juego democrático.

Si esto último es cierto, el análisis debe ir más allá de los moldes tradicionales y profundizar el sentido mismo de la democracia latinoamericana.

En realidad, a lo largo de nuestra historia el sistema democrático ha sido más una excepción que una regla. Algunos estudiosos de Ia política Iatinoamericana se han referido a la democracia como un concepto susceptible de ser "ampliado" mediante la incorpora. ción gradual de nuevos sectores al sistema político (clases medias, proletariado urbano, masas rurales). De acuerdo con este análisis, luego de sucesivas etapas se pasaría de una primitiva y limitada democracia elitaria a una democracia moderna y de masas, con participación total.

Sin embargo, y de acucrdo al yit descripto funcionamiento del sistema global, parecería que las probabilidades de una mayor am. pliación han llegado a sus límites. En electo, puede percibirse con facilidad que las nuevas respuestas autoritarias surgen en los países con mayor grado de movilización y cultura política, y en donde existian, al menos teóricamente, posibilidades concretas para el establecimiento de una democracia de masas.

En síntesis, podriamos adclantar la siguiente hipótesis: el desarrollo de una democracia de masas en la periferia resulta incompatible con esta fase de la cvolución del sistema capitalista global, o, dicho de otra manera, es manifiesta Ia compatibilidad entre el sistema capitalista global con regimenes autoritarios (Brasil, Argentina, Chile) y democracias restringidas (México y Colombia).

Parecería, también que un mayor juego democrático es susceptible de ser "administrado" en ciertos casos especiales, y que la tendencia que conduce a la crisis del sistema puede dilatarse - acaso no en forma indefinida- "cuando el Estado dispone de recursos financieros cuantiosos provenicntes de la explotación de la riqueza mineral petrolífera'si?. Tal el caso de Venezuela, donde el proceso democrático iniciado en 1958 se mantiene sin altibajos y sin que se avizoren riesgos serios para los próximos años, a pesar del proyecto de desarrollo concentrador - similar al del resto de la regiónpuesto en práctica.

s:Prebiscit, RaúL, op. cit., pág. 22 a 26. 
3. El autoritarismo flexible no rechaza el sistema democrático, o, inversamente, que el Estado no asume como ideología el autoritarismo que practica. Así, aun reconociendo que la democracia constituye el mejor sistema conocido para gobernar hombres y países, no se la considera el marco adecuado para el logro de la paz social y el "reordenamiento" de la economía.

Esta concepción se distingue de la propuesta por Estados Unidos -a través de la Alianza para el Progreso- durante la década del 60 , que pretendía promover conjuntamente el desarrollo económico y la democracia formal. En la actualidad, al privilegiarse la gobernabilidad y estabilidad del sistema, la democracia aparece como una instancia ulterior, corolario del orden restaurado.

Otra de las tendencias que puede percibirse con claridad durante la última década es el fortalecimiento del papel del Estado. Como se sabe, la expansión del sector público y del aparato estatal constituyó una condición indispensable para el avance del proceso industrializador por sustitución de importaciones. Sin embargo, los nuevos desafíos económicos y políticos planteados al sistema -muchas veces al margen de los canales institucionales de participación (guerrilla, terrorismo urbano)-, han dado lugar a una expansión inédita de las funciones del Estado y a modificaciones importantes en su estructura. Así, a pesar del clásico principio libcral de subsidiariedad del Estado -que sigue siendo ardorosamente defendido por la retórica oficial-, éste ha visto notoriamente incrementadas sus funciones, especialmente las empresariales, por dos motivos principales: 1) la ausencia de inversiones privadas en los sectores básicos de la economía; y 2) la necesidad de coordinar su estrategia con la de las compañías transnacionales, e incluso competir con ellas en razón de que sus inversiones se concentran en los sectores más dinámicos.

Como fuera señalado por Lowenthal, "el experimento socialista de Cuba proporciona, por supuesto, el ejemplo más extremo, pero hasta en Brasil los gastos del gobierno consumen ahora el $37 \%$ del Producto Bruto Nacional, comparado con el $17 \%$ en 1950, y el Estado brasileño juega un papel empresarial en la dinámica de la intermediación de los sectores de bienes de capital. En Perú, la posición del Estado en las inversiones nacionales totales aumentó de un 13\% en 1965 a más del $50 \%$ en 1973. En Venezuela, que en un tiempo 
fue un bastión capitalista, las empresas estatales tienen a su cargo los sectores petroleros, petroquímicos y del acero"'38.

A modo de sintesis, resulta útil resumir las tendencias observables en la región. Esto llevaría a incorporar al menos las siguientes:

-mantenimiento y profundización, en algunos casos, de las características estructurales del subdesarrollo latinoamericano (marginalidad, estancamiento, desnacionalización económica y cultural);

-mantenimiento de un modelo de desarrollo excluyente, concentrador y conflictivo;

-evolución hacia el establecimiento de regimenes polfticos autoritarios flexibles (afinidad electiva entre autoritarismo y capitalismo oligopólico tecno-industrial). Dentro de esta tendencia es importante destacar tres notas: a) sentido de la dominación autoritaria (base social y políticas implementadas); b) sentido actual de la oposición autoritarismo-democracia; y c) creencia en la incompatibilidad de impulsar en forma conjunta el desarrollo económico y el desarrollo democrático;

- comienzo de una nueva etapa de desarrollo hacia afuera, producto de la estrechez de los mercados internos y el agotamiento del modelo de sustitución fácil de las importaciones;

-fortalecimiento del rol del Estado y fundamentalmente de sus actividades empresariales;

-homogeneización, en el espacio latinoamericano, del tipo de regímenes políticos autoritarios;

-impulso en favor de políticas económicas sustentadas en una filosofía común (liberalismo económico) .

\section{CONSIDFRACIONES FINALFS}

De acuerdo con la situación y tendencias delineadas en los párrafos precedentes, pueden formularse algunas reflexiones acerca de los posibles cursos de acción que habrán de implementar los países mayores de la región durante los próximos años.

Ya se ha puesto de relieve que el Sur, en sus negociaciones con el Norte, ha mantenido una actitud solidaria. Sin embargo, los intereses diversos y a veces contrapuestos existentes en su seno reducen en el futuro las posibilidades de acciones coordinadas y homogéneas.

${ }^{88}$ Lowenthal, Abraham: "El fin de la presunción hegemónica", en Estudios Internacionales, Buenos Aires, 1977, vol. 37, pág. 57. 
En el Norte, por su parte, se perciben posiciones rigidas a nivel de la élite en cuanto a permitir el acceso de otras naciones en el círculo privilegiado de las que detentan el poder de decisión sobre los asuntos de mayor trascendencia internacional. No obstante, la conciencia de los potenciales desafíos al orden actual provenientes de algunos países intermedios, facilitan la apertura hacia vias de acceso e inserción privilegiadas.

De este modo, existen en nuestra opinión posibilidades concretas de alianzas selectivats entre el Norte y algunas potencias intermedias del Sur, que incluirían a los países mayores de América Latina. Puede observarse que las élites dirigentes de esos paises no sólo aceptan, sino que comparten la mayoría de las idcas, crencias y símbolos gestados por el sistemat cultural del Norte, incluidos por otra parte, dentro de los tradicionales valores del munclo occidental. Contrario sensu, rechizan o son indiferentes a los valores sostenidos por otros países del Jercer Mundo -fundamentalmente de Asia y Africa-, con quienes no tienen mayores puntos de contacto cultural y racial.

Aceptan y comparten con el Norte, además, la idea de que el mejor sistema económico es el liberal, basato en el mercado libre y la libre empresa. Esta filosofía común constituye un importante elemento de contacto con el mundo desarrollado, ya que lit negación de los principios del liberalismo económico (que caracteriza a ciertos grupos radicalizados del Sur) conduciría a posiciones de enfrentamiento que las élites no estín dispuestas a adoptar.

Por otra parte, si bien se aprecian divergencias entre los grupos políticos del Norte y ciertos gobiernos militares de América Latina en temas relacionados con los derechos humanos, la libertad de prensa, etc., en nuestra opinión las realidades económicas irán venciendo estas incompatibilidades políticas relacionadas con el mejor modo de defender los valores de Occidente.

De la posición de "low profile" adoptada por los países mayores respecto de la integración, puede inferirse, más allá de la retórica, que las alternativas of recidas por los procesos de integración autonomizante -que incluso darían viabiliclad colectiva a los países de menor desarrollo del continente- han sido dejadis de lado en esta etapa. Por el contrario, se percibe una peligrosa tendencia, dentro de las potencias mayores, proclive a la formación de esferas de influencia que atentan contra la filosofía de la integración solidaria e igualitaria. 
Así, la convicción compartida por la mayoría de los estudiosos de Américit Latina en el sentido de que sólo los grandes espacios integrados desempeñarán en el futuro roles protagónicos, y que el único camino para superar las relaciones asimétricas de dominación es la asociación autonomizante ${ }^{39}$, crea interrogantes difíciles de satisfacer sobre el porvenir autónomo de los paises de la región.

No obstante, a pesar de las coincidencias con el Norte, los países intermedios tienen intereses que los acercan visiblemente al Sur.

En primer término, y desde el punto de vista geopolítico, la calidad de sus relaciones con los países del Sur es un elemento muy importitnte de su política exterior. Además, la implementación de ciertas propuestas del Nori les proporcionarian beneficios indiscutibles en el plano económico. El debilitamiento de las barreras comerciales, las facilidades de acceso a la tecnología de los países desarrollados y la defensa del valor de las materias primas constituyen - entre otros- temas de interés directo para los países intermedios.

En otro orden de cosis, el resto de los países del Tercer Mundo interesa a los intermedios en un sentido muy parecido al manifestado por el Norte en relación con el conjunto del bloque Sur: como mercados para sus exportaciones y como terreno fértil para la expansión de sus inversiones en el cxterior. A ello debe agregarse que cstos países son potenciales clientes de una tecnología menos sofisticada y más adecuada a sus necesidades, que las potencias intermedias están en condiciones de satisfacer.

Otro factor significativo es el respaldo político que los palses del Sur pueden proporcionar a las potencias intermedias en caso de conflictos específicos. Es un hecho reconocido, por ejemplo, que la solidaridad revelada por los Estados africanos y asiáticos con la posición argentina en materia de recursos naturales compartidos (onc, Asamblea Gencral, 1973) fue un elemento decisivo en la revisión de la estrategia brasileña respecto de Africa, en el sentido de un mayor acercamiento aun a costa de su tradicional vinculación con Portugal.

sháase Puig Juan Caulos: "Integración y Autonomfa. A propósito de la reunión clel Foro Latinoamcricano de Caracas", en Revista Argentina de Relaciones Inlernacionales, Año I, $N Q 3$, Buenos Aircs, scptiembre/diciembre de 1975, pág. 8. En un sentido concordante se expresan Guillermo O'Donnell y Delfina Linck cuando sugicen que la estrategia fundamental de los dependientes es la ilianza contra el dominante. (Al respecto, véase O'Donell, Guillermo y Linck, Delfina, Dependencia y autonomía, Amorrortu, 1973, pág. 5l). 
Por el juego de los factores mencionados, es previsible en nuestra opinión que los países más fuertes de la región seguirán una política de tipo pendular que, sin enajenarles la solidaridad del Sur, favorezca su creciente inserción en el Norte. En este sentido, es de imaginar que orientarán la búsqueda de su inserción elitaria en el sistema (cooptación consentida) mediante alianzas múltiples y pluridireccionales, las que, sin embargo, no les harán perder de vista su norte: el mundo desarrollado. 